Факторы, влияющие на охват вакцинацией против пневмококковой инфекции детей первого года жизни

\author{
на начальных этапах вакцинации
}

\author{
Н.Н. Филатов ${ }^{1,2}$, М.П. Костинов ${ }^{1,2}$, Т.Н. Елагина ${ }^{1}$, М.Н. Локтионова ${ }^{1}$, Е.В.Лисицина ${ }^{3}$, \\ Ю.Б.Новикова ${ }^{3}$
}

\author{
${ }^{1}$ ФГАОУ ВО «Первый МГМУ им. И.М. Сеченова» Минздрава России, Москва \\ ${ }^{2}$ ФГБНУ «Научно-исследовательский институт вакцин и сывороток им. \\ И.И. Мечникова", Москва \\ ${ }^{3}$ ГБУЗ «Щербинская городская больница ДЗМ», Москва
}

\begin{abstract}
Резюме
На примере территорий новообразованных административных округов Москвы рассмотрены факторы, оказывающие влияние на вакцинацию против пневмококковой инфекции (ПИ). Выявлено недостаточное обеспечение вакциной для достижения необходимого уровня охвата: в 2014 году могли быть двукратно привиты 67,57\% детей; в 2015 году количество вакцины могло обеспечить двукратной вакцинацией 33,84\% детей первого года жизни. Однако действительное количество привитых детей оказалось значительно ниже (0,23\% - в 2014 г. и 20,85\% - в 2015 г.). При анкетировании врачей с целью определения уровня знаний и приверженности к вакцинации против Пи установлена недостаточная осведомленность в вопросах эпидемиологии, клинических проявлений и методах иммунопрофилактики Пи. Выявлено положительное отношение родителей к вакцинации против ПИ. Отмечен интерес родителей к возможностям иммунопрофилактики против ПИ на фоне недостаточного уровня информированности об ее проявлениях. Так 74,5\% родителей, чьи дети не имеют прививки против Пи, хотели бы начать вакцинацию, однако часть из них нуждаются в дополнительной информации (29,41\% родителей).
\end{abstract}

Ключевые слова: пневмококковая инфекция, пневмококковая конъюгированная вакцина, охват вакцинацией, факторы, влияющие на вакцинацию

\title{
Factors that Influence the Coverage of Vaccination against Pneumococcal Infections of Children up to 1 Year Old of Age at the Starting Phase of Vaccination
}

N.N. Filatov ${ }^{1,2}$, M.P. Kostinov ${ }^{1,2}$, T.N. Elagina ${ }^{1}$, M.N. Loktionova ${ }^{1}$, E.V. Lisitsyna ${ }^{3}$, Y.B. Novikova ${ }^{3}$

${ }^{1}$ Federal State Autonomous Educational Institution of Higher Education I.M. Sechenov First Moscow StateMedical University of the Ministry of Health of the Russian Federation.

${ }^{2}$ I.I. Mechnikov Research Institute of Vaccines and Sera of Russian Academy of Sciences, Moscow

${ }^{3}$ State Budgetary Institution "Shcherbinsky City Hospital Department of Healthcare", Moscow

\section{Abstract}

Whereas the quality of the program depends on promptness, full coverage, vaccination schedule abidance. Taking new Moscow regions as an example there have been studied factors influencing vaccination against Pneumococcal infection (PI). Insufficient provision of the vaccine to reach the desired level of coverage has been detected: in 2014 only $67.57 \%$ of liable children could receive double vaccination; the available quantity of vaccine in 2015 was able to provide 33. 84\% of children up to 12 months old with double vaccination. However, the actual number of children vaccinated turned to be much lower (0.23\% in 2014 and 20.85\% in 2015). The survey of the doctors with the purpose of defining the level of knowledge and commitment to the vaccination against PI has shown a modest level of epidemiology, clinical implications, Plimmunoprophylaxis method awareness. Parental attitude towards PI vaccination has been estimated as positive. Parental interest to opportunities of immunoprophylaxis against PI is worthwhile noting despite the insufficient level of knowledgeability of its effects. Hence $74.5 \%$ of parents whose children are not vaccinated against PI would like to start vaccination, however a part of them look into receiving more information (29.41\% parents).

Key words: pneumococcal infection, pneumococcal conjugate vaccine, vaccination coverage, factors influencing vaccination

\section{Введение}

Пневмококковая инфекция одна из самых распространенных причин смертности от инфекционных болезней, которые могут быть предотвращены с помощью вакцинопрофилактики. ПИ вызывает ряд заболеваний: от сравнительно легких, широ- ко распространенных неинвазивных форм (острый отит, синусит), до наиболее тяжелых, с высокими уровнями летальности инвазивных форм (менингит, бактериемия, пневмония). Всемирная организации здравоохранения рекомендует включение пневмококковых конъюгированных вакцин (ПКВ) 
в программы иммунизации детского населения повсеместно с учетом бремени болезни на локальном и региональном уровне, распределения случаев заболеваний по возрастам [1].

В Российской Федерации проблема ПИ является чрезвычайно актуальной $[2,3]$. Несмотря на низкий уровень диагностики и отсутствие системы учета случаев ПИ в стране, проведенные за последние 20 лет исследования, в том числе серотипового пейзажа основных форм заболевания, подтвердили для России актуальность введения иммунизации для детей первых лет жизни и лиц из групп риска [4 - 6].

При расширении Национальной программы иммунизации в масштабах отдельно взятого государства условно можно выделить три периода [7]. Первый период - время до внедрения массовой вакцинации, когда иммунобиологический препарат зарегистрирован и применяется в частной системе здравоохранения или же на региональном уровне. ПКВ доступны в России с 2009 года, и некоторые субъекты РФ имеют опыт применения их в рамках региональных программ для вакцинации лиц из групп риска $[8,9]$.

Следующий условный период представляет собой время от момента внедрения массовой вакцинации до достижения требуемых уровней охвата профилактическими прививками. Например, в США семивалентная ПКВ применяется с 2000 года: через 9 месяцев уровень охвата 3 прививками или более составлял $28,3 \%$ среди детей в возрасте 7 месяцев, и 54,1\% - в возрасте 6 месяцев[10]. В Бразилии вакцинация десятивалентной ПКВ стартовала в июне 2010 года: уровень охвата через 8 месяцев достиг 54\% среди детей в возрасте до 6 месяцев, 40,7\% -среди детей 7 - 11 месяцев и 88,8\% - детей 12 - 15 месяцев [11].

При достижении требуемого уровня охвата в декретированных возрастах становится возможным изучение эпидемиологической, клинической и экономической эффективности проводимой массовой иммунизации (последний, условно выделяемый период). В ряде стран, внедривших в национальные программы иммунизации ПКВ, доказаны эффективность и положительное влияние вакцинации против ПИ на общественное здоровье [1, 13,14].

Приказом Министерства здравоохранения от 21.03.14 № 125н в Национальный календарь профилактических прививок введена вакцинация против ПИ детей первого года жизни по схеме; в возрасте 2 и 4,5 месяцев с последующей ревакцинацией в 15 месяцев.

Ключевыми показателями эффективности иммунизации с эпидемиологической точки зрения являются соблюдение схемы вакцинации, уровень охвата (не менее 85 - 95\% от целевой когорты) [12], которые в свою очередь зависят от целого ряда факторов (экономических, административных, медицинских, социальных) [15]. Ресурсное обеспечение, профессиональная подготовка специалистов, работающих в области иммунопрофилактики [16], отношение населения (информированное добровольное согласие) к проводимым профилактическим мероприятиям играют важную роль в достижении эффекта от иммунизации.

Цель работы - оценить уровень охвата профилактическими прививками против ПИ и влияние ряда факторов на охват на начальных этапах массовой вакцинации на примере территорий новообразованных административных округов Москвы.

\section{Материалы и методы}

Для выполнения поставленной цели использовались следующие данные: официальной учетно-отчетной документации о проведенных профилактических прививках (форма № 5); отчетов о расходовании иммунобиологических препаратов; переписи детского населения (2014 - 2015 гг.), а также результаты анкетирования врачей медицинских организаций и родителей Троицкого и Новомосковского административных округов (ТиНАО) других административных округов Москвы и Московской области. $\mathrm{K}$ изучаемым факторам относили - обеспеченность вакциной, уровень знаний и отношение к вакцинации против пневмококковой инфекции врачей и родителей детей первых лет жизни.

Анкетирование врачей проводилось в конце 2015 - начале 2016 года, при ответе на вопросы предоставлялась возможность выбрать от одного до нескольких вариантов. В опросе приняли участие педиатры ( $\mathrm{n}=33)$ и врачи других специальностей (терапия, эпидемиология, отоларингология, офтальмология, неврология и пр.; $n=28$ ) ТиНАО, а также педиатры других административных округов (АО) Москвы (юго-западный, центральный, восточный, западный АО) и московской области ( $\mathrm{n}=44)$. Всего опрошено 105 врачей, из них 77 педиатров.

В начале 2016 года было организовано анкетирование родителей $(\mathrm{n}=68)$ в одном из лечебных учреждений ТиНАО. Опрос проводился на приеме у педиатра, а также непосредственно рядом с прививочным кабинетом.

При статистической обработке при расчете доверительных интервалов для долевых и частотных значений полученных результатов использовался метод Уилсона.

\section{Результаты и обсуждение}

В соответствии с Национальным календарем профилактических прививок РФ вакцинации против ПИ подлежат все дети, рожденные с 1 января 2014 года [12]. Число родившихся и охват вакцинацией против ПИ детей первого года жизни на территории Троицкого и Новомосковского административных округов (ТиНАО) в 2014 и 2015 годах отображены в таблице 1.

Первое поступление вакцины для профилактики ПИ состоялось в сентябре 2014 года в количестве достаточном для двукратной вакцинации 67,57\% 
Таблица 1.

Охват профилактическими прививками против ПИ (на территории ТиНАО в 2014 - 2015 гг.)

\begin{tabular}{|c|c|c|}
\hline Показатели & 2014 год & 2015 год \\
\hline Число родившихся & 2407 & 3141 \\
\hline Охват первой вакцинацией (\%) & $16,22^{\star}$ & 6,91 \\
\hline Охват полной вакцинацией (\%) & $0,23^{*}$ & 20,85 \\
\hline Непривитые (\%) & $83,56^{\star}$ & 72,24 \\
\hline
\end{tabular}

Примечание: *от числа детей, рожденных в июне-июле 2014 года (подлежащих вакцинации в 2 и 4,5 месяца согласно Национальному календарю профилактических прививок РФ на момент поступления вакцины)

детей рожденных в июне-июле 2014 года (подлежащих вакцинации в 2 и 4,5 месяца согласно Национальному календарю на момент поступления вакцины). Однако спустя 9 месяцев от внедрения вакцинации против ПИ уровень охвата составил лишь 0,23\%, что несоизмеримо с уровнями охвата детей до 6 месяцев за аналогичный период в других странах: 54,1\% - в США; 54\% - в Бразилии.

В 2015 году с учетом неизрасходованного количества вакцины в 2014 году и вновь поступившего в течение года максимально можно было охватить двукратной вакцинацией 33,84\% детей первого года жизни, однако привито было только 20,85\%. Таким образом, очевидно наличие иных факторов, оказывающих влияние на охват вакцинацией против ПИ, таких как приверженность и осведомленность врачей и родителей в вопросах иммунопрофилактики против ПИ.

Среди опрошенных врачей стаж работы более 10 лет имели 90,91\% педиатров ТиНАО и 84,09\% других административных округов (АО) Москвы и Московской области (МО), 82,14\% врачей других специальностей ТиНАО. О включении вакцинации против ПИ в Национальный календарь профилактических прививок информированы все педиатры из других АО и московской области, 96,97\% педиатров ТиНАО и 82,14\% врачей других специальностей ТиНАО (табл. 2). Вероятно, это связано с тем, что вопросы рутинной вакцинации значительно реже входят в сферу деятельности врачей не педиатрического профиля. При том, что по вопросам иммунопрофилактики ПИ в РФ имеется достаточное количество инструктивно-методических документов [5, 17 - 20].

Директивность Национального календаря профилактических прививок переносят на практику только 69,7\% педиатров и 57,14\% врачей иных специальностей ТиНАО, отмечая, что здоровому ребенку в возрасте 2 месяцев необходимо назначать вакцинацию против ПИ. Некоторая часть педиатров (6,06\%) ТиНАО и других АО и МО (18,18\%) отметили два варианта: вакцинация проводится в обязательном порядке и по пожеланию родителей. Такая ситуация складывается в силу ограниченного количества вакцины против ПИ и невозможности привить каждого ребенка декретировпнного возраста, сомнений/неосведомленности родителей и отказом от проведения "необязательной" прививки.

Для вакцинации детей первых лет жизни в РФ используются зарубежные 10- и 13-валентные ПКВ. Для вакцинации лиц из групп риска по заболеваемости тяжелыми формами ПИ в РФ применяется 23-валентная полисахаридная вакцина, назначение которой возможно лицам старше 2 лет. В результате анкетирования выявлена низкая информированность педиатров о возможности при-

Таблица 2.

Результаты анкетирования педиатров ТиНАО и других АО Москвы и МО, а также врачей иных специальностей ТиНАО (ДИ 95\%)

\begin{tabular}{|c|c|c|c|c|}
\hline \multirow[b]{2}{*}{ Врачи/территории } & \multirow{2}{*}{$\begin{array}{c}\text { Осведомлены } \\
\text { о внесении } \\
\text { вакцинации против } \\
\text { ПИ в Национальный } \\
\text { календарь } \\
\text { профилактических } \\
\text { прививок РФ }\end{array}$} & \multicolumn{3}{|c|}{$\begin{array}{l}\text { Отметили, что здоровому ребенку } \\
\text { в } 2 \text { месяца вакцинация против Пи }\end{array}$} \\
\hline & & $\begin{array}{c}\text { назначается в } \\
\text { обязательном } \\
\text { порядке }\end{array}$ & $\begin{array}{c}\text { проводится } \\
\text { по пожеланию } \\
\text { родителей }\end{array}$ & не проводится \\
\hline Педиатры ТиНАО & $\begin{array}{c}96,97 \% \\
(84,68-99,46 \%)\end{array}$ & $\begin{array}{c}69,7 \% \\
(52,66-82,62 \%)\end{array}$ & $\begin{array}{c}36,36 \% \\
(22,19-53,38 \%)\end{array}$ & $\begin{array}{c}0 \% \\
(0-10,43 \%)\end{array}$ \\
\hline \begin{tabular}{|l} 
Других \\
специальностей ТиНАО
\end{tabular} & $\begin{array}{c}78,57 \% \\
(60,46-89,79 \%)\end{array}$ & $\begin{array}{c}57,14 \% \\
(39,07-73,49 \%)\end{array}$ & $\begin{array}{c}50 \% \\
(32,63-67,37 \%)\end{array}$ & $\begin{array}{c}10,71 \% \\
(3,71-27,2 \%)\end{array}$ \\
\hline $\begin{array}{l}\text { Педиатры других АO } \\
\text { Москвы и МО }\end{array}$ & $\begin{array}{c}100 \% \\
(91,97-100 \%)\end{array}$ & $\begin{array}{c}81,82 \% \\
(68,04-90,49 \%)\end{array}$ & $\begin{array}{c}31,82 \% \\
(20-46,56 \%)\end{array}$ & $\begin{array}{c}2,27 \% \\
(0,4-11,81 \%)\end{array}$ \\
\hline Всего & $\begin{array}{c}93,33 \% \\
(86,87-96,73 \%)\end{array}$ & $\begin{array}{c}71,43 \% \\
(62,15-79,19 \%)\end{array}$ & $\begin{array}{c}38,10 \% \\
(29,38-47,65 \%)\end{array}$ & $\begin{array}{c}3,81 \% \\
(1,49-9,39 \%)\end{array}$ \\
\hline
\end{tabular}




\begin{tabular}{|c|c|c|c|c|c|c|c|c|}
\hline & \multicolumn{2}{|c|}{$\begin{array}{c}\text { Для вакцинации детей против } \\
\text { Пи согласно Национальному } \\
\text { календарю профилактических } \\
\text { прививок возможно использо- } \\
\text { вать: }\end{array}$} & \multicolumn{3}{|c|}{ Возможные схемы вакцинации против пи детей разных } \\
врозрастных групп
\end{tabular}

менения 10-валентной ПКВ для профилактики ПИ (табл. 3). Также 27,27 и 25\% педиатров ТиНАО и других АО и МО считают возможным применение 23-валентной полисахаридной вакцины для вакцинации согласно Национальному календарю профилактических прививок.

Согласно инструкциям к ПКВ возможна как трехкратная вакцинация в первом полугодии жизни $(3+1)$, так и двукратная $(2+1)$, с последующей в каждом случае ревакцинацией на втором году жизни. Имеющиеся в РФ инструктивно-методические документы по вопросам иммунопрофилактики против ПИ предписывают использовать схему $3+1$ только для детей из групп риска по развитию тяжелых форм ПИ (дети с иммунодефицитами, ВИЧинфицированным, недоношенным с массой тела при рождении менее 2000 г и др. [5]). При анкетировании педиатров выявлено, что у них отсутствует понимание в чем состоит различие двух схем вакцинации детей первого полугодия жизни. Так, большинство педиатров ТиНАО выбрали схему $2+1$, регламентированную Национальным календарем профилактических прививок, в то время как большинство педиатров других АО и МО отметили схему $3+1$, допустимую для вакцинации детей из групп риска. Более высокий уровень знаний отмечен у педиатров других АO и МО в в отношении схем "догоняющей" вакцинации детей второго полугодия жизни, с года до двух и в возрасте 2 - 5 лет. Следует отметить низкую осведомленность во всех трех опрошенных группах врачей о двукратной схеме вакцинации детей в возрасте 2 - 5 лет, которая проводится согласно инструкции ПКВ 10. Среди врачей иных специальностей выявлен еще более низкий уровень знаний о применении используемых в РФ препаратов для вакцинации против ПИ.

S. pneumoniae может вызывать как инвазивные, так и неинвазивные формы заболевания. Инвазивные формы ПИ - одна из ведущих причин смертности детей в возрасте до 5 лет, а также развития инвалидности после перенесенной тяжелой формы инфекции. Неинвазивные формы ПИ имеют менее тяжелые проявления, но их частота значительно выше [1, 4, 15, 21]. При оценке знания врачей о клинических формах ПИ выявлена недостаточная осведомленность как об инвазивных (менингит - 67,6\% врачей), так и неивазивных формах (бронхит - 71,4\%, синусит - 60\%, конъюнктивит - 22,9\% врачей) (табл. 4).

В соответствии с зарубежными и российскими рекомендациями, выделяют группы риска по развитию тяжелых форм ПИ [4, 5, 22]. Педиатры меньше всего осведомлены о следующих группах риска - дети первого года жизни, рано переведенные на искусственное/смешанное вскармливание; реконвалесценты острого среднего отита, менингита; дети после операции по установке кохлеарного импланта; пациенты с иммунодефицитами, включая ВИЧ-инфицированных; недоношенные дети (табл. 5).

Среди родителей в анкетировании участвовали как мамы (86,76\%), так и папы (13,24\%). Средний возраст опрошенных родителей - 30 лет $(30,63 \pm 5,39)$. Среди опрошенных доля детей младше 1 года составила 44,12\%, от 1 до 2 лет $30,88 \%$. 
Таблица 4.

Результаты анкетирования педиатров ТиНАО и АО Москвы и МО, а также врачей других специальностей ТиНАО (ДИ 95\%)

\begin{tabular}{|c|c|c|c|c|c|c|}
\hline \multirow{2}{*}{$\begin{array}{c}\text { Врачи/ } \\
\text { территории }\end{array}$} & \multicolumn{6}{|c|}{ Вакцинация против ПИ снижает заболеваемость: } \\
\hline & пневмониями & отитами & бронхитами & синуситами & конъюнктивитами & менингитами \\
\hline $\begin{array}{l}\text { Педиатры } \\
\text { ТиНАО }\end{array}$ & $\begin{array}{c}100 \% \\
(89,57-100 \%)\end{array}$ & $\begin{array}{l}75,76 \% \\
(58,98- \\
87,17 \%)\end{array}$ & $\begin{array}{l}81,86 \% \\
(65,61- \\
91,39 \%)\end{array}$ & $\begin{array}{l}60,61 \% \\
(43,68- \\
75,32 \%)\end{array}$ & $\begin{array}{c}33,33 \% \\
(19,75-50,39 \%)\end{array}$ & $\begin{array}{l}69,70 \% \\
(52,66- \\
82,62 \%)\end{array}$ \\
\hline $\begin{array}{l}\text { Других } \\
\text { специальностей } \\
\text { ТиНАО }\end{array}$ & $\begin{array}{l}96,43 \% \\
(82,29- \\
99,37 \%)\end{array}$ & $\begin{array}{l}67,86 \% \\
(49,34- \\
82,07 \%)\end{array}$ & $\begin{array}{l}67,86 \% \\
(49,34- \\
82,07 \%)\end{array}$ & $\begin{array}{c}50 \% \\
(32,63- \\
67,37 \%)\end{array}$ & $\begin{array}{c}39,29 \% \\
(23,57-57,59 \%)\end{array}$ & $\begin{array}{l}53,57 \% \\
(35,81- \\
70,47 \%)\end{array}$ \\
\hline $\begin{array}{l}\text { Педиатры AO } \\
\text { Москвы и МO }\end{array}$ & $\begin{array}{c}100 \% \\
(91,97-100 \%)\end{array}$ & $\begin{array}{l}81,82 \% \\
(68,04- \\
90,49 \%)\end{array}$ & $\begin{array}{l}65,91 \% \\
(51,14- \\
78,12 \%)\end{array}$ & $\begin{array}{l}65,91 \% \\
(51,14- \\
78,12 \%)\end{array}$ & $\begin{array}{c}4,55 \% \\
(1,26-15,14 \%)\end{array}$ & $\begin{array}{c}75 \% \\
(60,56- \\
85,43 \%)\end{array}$ \\
\hline Всего: & $\begin{array}{c}99,05 \% \\
(94,8-99,83 \%)\end{array}$ & $\begin{array}{c}76,19 \%(67,21- \\
83,32 \%)\end{array}$ & $\begin{array}{l}71,43 \% \\
(62,15- \\
79,19 \%)\end{array}$ & $\begin{array}{c}60 \% \\
(50,44- \\
68,86 \%)\end{array}$ & $\begin{array}{c}22,86 \% \\
(15,87-31,76 \%)\end{array}$ & $\begin{array}{l}67,62 \% \\
(58,18- \\
75,81 \%)\end{array}$ \\
\hline
\end{tabular}

\section{Таблица 5.}

Результаты анкетирования педиатров ТиНАО и других АО Москвы и МО, а также врачей иных специальностей ТиНАО (ДИ 95\%)

\begin{tabular}{|c|c|c|c|c|c|c|c|}
\hline \multirow[b]{2}{*}{$\begin{array}{c}\text { Врачи/ } \\
\text { территории }\end{array}$} & \multicolumn{7}{|c|}{ К группам риска по заболеваемости ПИ относятся: } \\
\hline & $\begin{array}{c}\text { Дети в воз- } \\
\text { расте до } 5 \\
\text { лет }\end{array}$ & $\begin{array}{c}\text { Взрослые } \\
\text { старше } 65 \\
\text { лет }\end{array}$ & $\begin{array}{c}\text { Пациенты } \\
\text { с врожден- } \\
\text { ными или } \\
\text { приобре- } \\
\text { тенными } \\
\text { иммуноде- } \\
\text { фицитами, } \\
\text { включая } \\
\text { виЧ-инфи- } \\
\text { цированных }\end{array}$ & $\begin{array}{l}\text { Недоношен- } \\
\text { ные дети }\end{array}$ & $\begin{array}{c}\text { Дети, рано } \\
\text { переве- } \\
\text { денные на } \\
\text { смешанное/ } \\
\text { искусствен- } \\
\text { ное вскарм- } \\
\text { ливание }\end{array}$ & $\begin{array}{c}\text { Реконва- } \\
\text { лесценты } \\
\text { острого } \\
\text { среднего от- } \\
\text { ита, менин- } \\
\text { гита, после } \\
\text { установки } \\
\text { кохлеарного } \\
\text { трансплан- } \\
\text { танта }\end{array}$ & $\begin{array}{c}\text { Длитель- } \\
\text { но и часто } \\
\text { болеющие } \\
\text { дети }\end{array}$ \\
\hline $\begin{array}{l}\text { Педиатры } \\
\text { ТиНАО }\end{array}$ & $\begin{array}{c}93,94 \%(80,39 \\
-98,32 \%)\end{array}$ & $\begin{array}{c}66,67 \%(49,61 \\
-80,25 \%)\end{array}$ & $\begin{array}{l}78,79 \% \\
(62,25- \\
89,32 \%)\end{array}$ & $\begin{array}{l}96,97 \% \\
(84,68- \\
99,46 \%)\end{array}$ & $\begin{array}{l}66,67 \% \\
(49,61- \\
80,25 \%)\end{array}$ & $\begin{array}{l}60,61 \% \\
(43,68- \\
75,32 \%)\end{array}$ & $\begin{array}{l}90,91 \% \\
(76,43- \\
96,86 \%)\end{array}$ \\
\hline $\begin{array}{l}\text { Других } \\
\text { специаль- } \\
\text { ностей ТиНАО }\end{array}$ & $\begin{array}{c}82,14 \%(64,41 \\
-92,12 \%)\end{array}$ & $\begin{array}{c}82,14 \%(64,41 \\
-92,12 \%)\end{array}$ & $\begin{array}{l}71,43 \% \\
(52,94- \\
84,75 \%)\end{array}$ & $\begin{array}{l}71,43 \% \\
(52,94- \\
84,75 \%)\end{array}$ & $\begin{array}{l}42,86 \% \\
(26,51- \\
60,93 \%)\end{array}$ & $\begin{array}{c}50 \% \\
(32,63- \\
67,37 \%)\end{array}$ & $\begin{array}{l}82,14 \% \\
(64,41- \\
92,12 \%)\end{array}$ \\
\hline $\begin{array}{l}\text { Педиатры } \\
\text { других АO } \\
\text { Москвы и МO }\end{array}$ & $\begin{array}{c}100 \%(91,97- \\
100 \%)\end{array}$ & $\begin{array}{c}93,18 \%(81,77 \\
-97,65 \%)\end{array}$ & $\begin{array}{c}75 \% \\
(60,56- \\
85,43 \%)\end{array}$ & $\begin{array}{c}75 \% \\
(60,56- \\
85,43 \%)\end{array}$ & $\begin{array}{c}31,82 \% \\
(20-46,56 \%)\end{array}$ & $\begin{array}{l}59,09 \% \\
(44,41- \\
72,31 \%)\end{array}$ & $\begin{array}{c}100 \% \\
(91,97-100 \%)\end{array}$ \\
\hline Всего & $\begin{array}{l}93,33 \% \\
(86,87- \\
96,73 \%)\end{array}$ & $\begin{array}{c}81,9 \% \\
(73,46- \\
88,1 \%)\end{array}$ & $\begin{array}{l}75,24 \% \\
(66,19- \\
82,51 \%)\end{array}$ & $\begin{array}{l}80,95 \% \\
(72,4- \\
87,32 \%)\end{array}$ & $\begin{array}{l}45,71 \% \\
(36,51- \\
55,23 \%)\end{array}$ & $\begin{array}{l}57,14 \% \\
(47,59- \\
66,19 \%)\end{array}$ & $\begin{array}{l}92,38 \% \\
(85,68- \\
96,09 \%)\end{array}$ \\
\hline
\end{tabular}

Профилактические прививки своим детям проводят 95,6\% (ДИ 87,8 - 98,5\%) опрошенных родителей. Информацию о предстоящей прививке получают от врача 75,0\% (ДИ 63,6 - 83,8\%), 11,76\% (ДИ 6,1 - 21,5\%) предпочитают самостоятельно узнавать информацию перед проведением профилактических прививок и 16,18\% (ДИ 9,28 - 26,69\%) родителей полностью доверяют педиатру и не интересуются информацией о прививках. Больше половины опрошенных (64,71\%; ДИ 52,8 - 75\%) знают о расширении Национального календаря профилактических прививок. У 25\% (ДИ 16,2 - 36,4\%) опрошенных дети уже вакцинированы от ПИ, а 74,5\% (ДИ 61,1 - 84,5\%) родителей, чьи дети не привиты от ПИ, хотели бы начать данную вакцинацию. Однако 9,8\% (ДИ 4,3 - 21\%) родителей готовы к вакцинации после года или двух, а 29,41\% (ДИ 18,7 - 43\%) хотели бы узнать больше информации о прививке против ПИ.

\section{Выводы}

1. Охват вакцинацией против ПИ в 2014 и 2015 годах были крайне низким $(0,23$ и 20,85\% соответственно) по сравнению с другими странами после введения вакцинации против ПИ (28,3 - 54,1\% в США через 9 месяцев и 40,7 - 54\% в Бразилии через 8 месяцев). 
2. Ограниченное поступление вакцины для профилактики ПИ (33,84\% от необходимого количества в 2015 г.) в первую очередь не позволяет достичь необходимого уровня охвата профилактическими прививками.

3. Выявлена недостаточная информированность педиатров, а также врачей иных специальностей по вопросам эпидемиологии, клинических проявлений и схем иммунопрофилактики пневмококковой инфекции.

4. Необходимо проведение комплекса мероприятий по повышению знаний врачей в вопросах ПИ с обязательным последующим контролем.
5. Среди родителей выявлено положительное отношение к вакцинации против ПИ (73,53\%; ДИ 62,0 - 82,6\%), однако часть из них нуждается в дополнительной информации об иммунопрофилактике против ПИ (29,41\%), а 9,8\% опрошенных готовы вакцинировать детей в более отдаленные сроки.

Таким образом распространение информации в доступном изложении о пневмококковой инфекции: ее формах, тяжести, последствиях и возможностях иммунопрофилактики весьма актуально и не только среди родителей, но и медицинских рабоников.

\section{Литература}

1. World Health Organization.Weekly epidemiological record. Pneumococcal vaccines. WHO position paper. 2012. Fact sheet No.14, $2012 ; 87: 129$ - 144. Доступно на: http://www.who.int/wer

2. Королева И.С., Харит С.М., Рулева А.А., Перова А.Л., Сидоренко С.В. Пневмококковая инфекция в России - эпидемиологическая ситуация. Педиатрическая фармакология. 2010; 7 (4): 12 - 18.

3. Бремя пневмококковых заболеваний в России. Рекомендации расширенного заседания Совета экспертов, инициированного союзом педиатров России. Вопросы современной педиатрии. 2009; 8 (2): $104-108$.

4. Баранов А.А., Брико Н.И., Намазова-Баранова Л.С., Ряпис Л.А. Стрептококки и пневмококки. Ростов-на-Дону: Феникс. 2013.

5. Вакцинопрофилактика пневмококковой инфекции у детей. Баранова-Намазова Л.С., ред. Москва: Педиатръ; 2016.

6. Сидоренко С.В., Лобзин Ю.В., Харит С.М., Королева И.С., Таточенко В.К. Пневмококковая инфекция и современные возможности ее профилактики эпидемиологический обзор ситуации в мире и в России. Вопросы современной педиатрии. 2010; 9 (1): 62 - 69.

7. Afonso E.T., Minamisava R., Bierrenbach A.L., Escalante J.J.C., Alencar A.P., Domingues C.M. et al. Effect of 10-valent pneumococcal vaccine on pneumonia among children, Brazil. EmergInfectDis. 2013; 4. Доступно на: http://wwwnc.cdc.gov/eid/article/19/4/12-1198_article

8. Романенко В.В., Сомова А.В., Ковтун О.В. Первые уроки масштабной программы вакцинопрофилактики пневмококковой инфекции в Свердловской области. Педиатрическая фармакология. 2014; $11(1): 86$ - 90.

9. Ильина С.В., Белецкая О.А., Сабитов А.У., Черная Н.Л., Снегова Н.Ф., Салкина О.А. и др. Результаты оценки эффективности и безопасности применения конъюгированных пневмококковых вакцин в Российской Федерации. Эпидемиология и инфекционные болезни. Актуальные вопросы. 2013 ; 6: 55 - 59.

10. Smith P.J., Nuorti J.P., Singleton J.A., Zhao Z., Wolter K.M. Effect of Vaccine Shortages on Timeliness of Pneumococcal Conjugate Vaccination: Results From the 2001 - 2005 National Immunization Survey. Pediatrics. 2007; 120 (5): e1165 - e73. Доступно на: http://pediatrics.aappublications.org/content/120/5/ e1165.long

11. Saraiva F.O., Minamisava R., Vieira M.A., Bierrenbach A.L., Andrade A.L. Vaccination Coverage and Compliance with Three Recommended Schedules of 10-Valent Pneumococcal Conjugate Vaccine during the First Year of Its Introduction in Brazil: A Cross-Sectional Study. PLoSONE. 10 (6): e0128656. Доступно на: http://journals.plos.org/plosone/article?id=10.1371/journal.pone.0128656.

12. Резолюция заседания общественного Координационного совета по пневмококковой инфекции и вакцинации в России. Эпидемиология и вакцинопрофилактика. 2016; 1: $43-47$.

13. Макинтош Д.Д. Международный опыт применения 7-валентной конъюгированной пневмококковой вакцины. Педиатрическая фармакология. 2009; $6(2): 8-11$

14. Костинов М.П. Новая конъюгированная пневмококковая вакцина Превенар 13 - эффективная защита детей от пневмококковых заболеваний. Эпидемиология и вакцинопрофилактика. 2011; 6 (61): 99 - 107.

15. Шамшева О.В., Учайкин В.Ф., Медуницын Н.В. Клиническая вакцинология. Москва: гэОТАР-Медиа; 2016.

16. Ясинский А.А., Лыткина И.Н., Михеева И.В. К вопросу о профессиональной подготовке медицинских работников педиатрического профиля в области вакцинопрофилактики. Детские инфекции. 2011; 10 (2): 35 - 39.

17. Эпидемиология и вакцинопрофилактика инфекции, вызываемой Streptococcus pneumoniae. Методические рекомендации МР 3.3.1.0027-11. 2011.

18. Иммунизация полисахаридной поливалентной вакциной для профилактики пневмококковой инфекции. Методические рекомендации. МР 3.3.1. 2008.

19. Письмо Министерства здравоохранения Российской Федерации от 08.06.2015 №24-2-2031252 «По применению пневмококковой полисахаридной конъюгированной адсорбированной вакцины". Информационный вестник здравоохранения Самарской области. $2015 ; 27: 5$ - 8.

20. Руководство по клинической иммунологии в респираторной медицине. Костинов М.П., Чучалин А.Г., ред. Москва: АТМО; 2016.

21. Вакцины и вакцинация. Национальное руководство. Зверев В.В., Семенов Б.Ф., Хаитов Р.М., ред. Москва: ГЭОТАР-Медиа; 2011.

22. Костинов М.П., ПахомовД.В.Эффективностьи безопасность вакциныпревенарудетейи взрослыхгрупприска. Эпидемиология и Вакцинопрофилактика. 2010; 3 (52): $68-71$.

\section{References}

1. World Health Organization.Weekly epidemiological record. Pneumococcal vaccines. WHO position paper. 2012. Fact sheet No.14, $2012 ; 87: 129$ - 144. Available at: http://www.who.int/wer

2. Koroleva I.S., Kharit S.M., Ruleva A.A., Perova A.L., Sidorenko S.V. Pneumococcal infection in Russia: epidemiological situation. Pediarticheskaya pharmokologia [Pediatric pharmacology]. 2010; 7 (4): 12 - 18 (in Russian).

3. The burden ofpneumococcalinfectionsandthe directions of improving epidemiological surveillance in Russia. Voprosi sovremennoi pediatrii [Current pediatrics]. 2009; 8 (2): 104-108 (in Russian).

4. Baranov A.A., Briko N.I., Namazova-Baranova L.S.,Ryapis L.A. Streptococci and pneumococci.Rostov-on-Don: Fenix; 2013 (in Russian).

5. Vaccinal Prevention of Pneumococcal Infection in Children. Edit.: Namazova-Baranova L.S. Moscow: Pediatrician; 2016(in Russian).

6. Sidorenko S.V., LobzinYu.V., Kharit S.M., Korolyova I.S., Tatochenko V.K. Pneumococcal infection and modern opportunities of its prophylaxis - epidemiological review of situation in the world and Russia. Voprosi sovremennoi pediatrii [Current pediatrics]. 2010; 9 (1): 162 - 69 (in Russian).

7. Afonso E.T., Minamisava R., Bierrenbach A.L., Escalante J.J.C., Alencar A.P., Domingues C.M. et al. Effect of 10-valent pneumococcal vaccine on pneumonia among children, Brazil. EmergInfectDis. 2013; 4. Available at: http://wwwnc.cdc.gov/eid/article/19/4/12-1198_article

8. Romanenko V.V., Somova A.V., Kovtun O.V. The first lessons of a wide-scale pneumococcal infection vaccinal prevention program in the Sverdlovsk region. Pediarticheskaya pharmokologia [Pediatric pharmacology]. 2014; 11 (1): 86 - 90 (in Russian).

9. Ilyina S.V., Beletskaya O.A., Sabitov A.U., Chernaya N.L., Snegova N.F., Salkina O.A. et al. Theefficiency and safety of using pneumococcal conjugate vaccines in the Russian Federation: results of evaluation. pidemiologi I Infekcionnye Bolezni. Aktual'nye voprosy. [Epidemiology and Infection Diseases.Topical issues]. 2013; 6: 55 - 59 (in Russian).

10. Smith P.J., Nuorti J.P., Singleton J.A., Zhao Z., Wolter K.M. Effect of Vaccine Shortages on Timeliness of Pneumococcal Conjugate Vaccination: Results From the 2001 - 2005 National Immunization Survey. Pediatrics. 2007; 120 (5): e1165 - e73. Available at: http://pediatrics.aappublications.org/content/120/5/e1165.long

11. Saraiva F.O., Minamisava R., Vieira M.A., Bierrenbach A.L., Andrade A.L. Vaccination Coverage and Compliance with Three Recommended Schedules of 10-Valent Pneumococcal Conjugate Vaccine during the First Year of Its Introduction in Brazil: A Cross-Sectional Study. PLoSONE. 10 (6): e0128656. Available at: http://journals.plos.org/plosone/article?id=10.1371/journal.pone.0128656. 
12. Resolution of the meeting of the public coordination council on pneumococcal infection and vaccination in Russia. Epidemiologia i Vaccinoprofilaktika. [Epidemiology and Vaccinal Prevention]. 2016; 1: 43 - 47 (in Russian).

13. McIntosh D.G. International experience with 7-valent pneumococcal conjugate vaccine. Pediarticheskaya pharmokologia [Pediatric pharmacology]. 2009; 6 (2): 8 - 11 (in Russian).

14. Kostinov M.P. The new conjugate pneumococcal vaccine prevnar 13 - the effective protection of children against pneumococcal disease. Epidemiologia i Vaccinoprofilaktika. [Epidemiology and Vaccinal Prevention]. 2011; 6 (61): 99 - 107 (in Russian).

15.S hamsheva O.V., Uchaikin V.F., Medunitsyn N.V. Clinical vaccinology. Moscow: GEOTAR-Media; 2016 (in Russian).

16. Yasinsky A.A., Lytkina I.N., Mikheyeva I.V. On the issue of professional training of medical staff in the area of pediatric vaccine prophylaxis. Detskie infekcii. [Children Infections]. 2011; 10 (2): 35 - 39 (in Russian).

17. Epidemiologyand vaccinal prevention of pneumococcal infection. Methodical recommendations. MI 3.3.1.0027-11.2011 (in Russian).

18. Immunization with using pneumococcal polysaccharide vaccinefor the prevention of pneumococcal disease. Methodical recommendations. MI 3.3.1. 2008 (in Russian).

19. Letter of Ministry of Health of the Russian Federation from 08.06.2015 №24-2-2031252 «By the use of pneumococcal polysaccharide conjugate adsorbed vaccine" Health Information Gazette Samara region. 2015; $27: 5$ - 8 (in Russian).

20. Kostinov M.P., Chuchalin A.G., edit. Manual of Clinical Immunology in respiratory medicine. Moscow: ATMO; 2016 (in Russian).

21. Zverev V.V., Semenov B.F., Khaitov R.M., edit. Vaccines and vaccination. National manual. Moscow: GEOTAR-Media; 2011 (in Russian)

22. Kostinov M.P., Pahomov D.V. Efficacy and Safety of the Vaccine Prevenar in Children and Adults at Risk. Epidemiologia i Vaccinoprofilaktika. [Epidemiology and Vaccinal Prevention]. 2010; 3 (52): 68 - 71 (in Russian).

Изменение активности кислой и щелочной фосфатаз в иммунокомпетентных органах - критерий оценки эффективности иммунобиологических препаратов

\author{
O.В. Юрьева (olga.yur1963@gmail.com), В.И. Дубровина (dubrovina-valya@mail.ru), \\ А.В. Корнева, Т.П. Старовойтова, Т.А. Иванова, В.Б. Николаев, С.В. Балахонов
}

ФКУЗ «Иркутский научно-исследовательский противочумный институт» Роспотребнадзора, (adm@chumin.irkutsk.ru)

\title{
Резюме
}

Изучена динамика активности кислой фосфатазы и щелочной фосфатазы в тимусе и селезенке лабораторных мышей, иммунизированных препаратами клеточных стенок Francisella tularensis разных подвидов. Препараты клеточных стенок подвидов $F$. tularensis subsp. mediaasiatica A-61(385) и F. tularensis subsp. novicida B-399 A-Cole (386) стимулировали повышение активности кислой и щелочной фосфатазы в более ранние сроки (на 7 сутки) после иммунизации, чем остальные. Эти препараты также показали высокую протективную активность. На основании проведенного исследования можно заключить, что изучение динамики активности кислой и щелочной фосфатаз в иммунокомпетентных органах может служить одним из критериев оценки эффективности иммунобиологических препаратов.

Ключевые слова: туляремия, клеточная стенка, фосфатаза, тимус, селезенка

\section{Change in the Activity of Acidic and Alkaline Phosphatases in Immunocompetent Organs - a Criterion for Evaluating the Effectiveness of Immunobiological Preparations}

O.V. Yurieva (olga.yur1963@gmail.com), V.I. Dubrovina (dubrovina-valya@mail.ru), A.V. Korneva, T.P. Starovoitova,

T.A. Ivanova, V.B. Nikolaev, S.V. Balakhonov

Federal Budgetary Healthcare Facility «Irkutsk Antiplague Research Institute» of Federal Service for Surveillance on Consumer Rights Protection and Human Wellbeing, adm@chumin.irkutsk.ru

\section{Abstract}

Dynamics of acidic and alkaline phosphatase activities was examined in thymus and spleen of laboratory mice immunized by cell wall preparations of Francisella tularensis of different subspecies. Cell wall preparations of two subspecies: $F$. tularensis subsp. mediaasiatica A-61(385) and F. tularensis subsp. novicida B-399 A-Cole (386) stimulated the rise of acidic and alkaline phosphatase activities in earlier time (7 days) after immunization than the others. It was correlated with their protective activity. On the basis of the results it is concluded that the studying of the acidic and alkaline phosphatase activities in immunocompetent organs can serve as one of the criteria for evaluation of efficiency of immunobiological preparations.

Key words: Francisella tularensis, cell wall, phosphatase, thymus, spleen

\section{Введение}

Известно, что возбудитель туляремии является внутриклеточным паразитом, способным длитель- ное время персистировать в клетках макроорганизма, вызывая хронизацию инфекционного процесса и рецидивы. Такая особенность F. tularensis 